\title{
Los albores del periodismo veracruzano: el Jornal Económico Mercantil de Veracruz, como fuente histórica
}

Verónica Zárate Toscano

INSTTTUTO MORA

\begin{abstract}
Análisis del primer periódico especializado en temas económicos publicado en el puerto de Veracruz en la última etapa del periodo virreinal. Se estudian los objetivos, el editor, los autores, los lectores, el financiamiento y los tipos de noticias, resaltando la utilidad que pueden tener para diversos estudios históricos.
\end{abstract}

\section{Preliminar}

L a prensa es una importante fuente de información para investigar diversos temas y épocas. Muchos estudios han tenido como base el análisis de los periódicos considerando que, como cualquier fuente histórica, tienen sus limitaciones. Se les puede utilizar provechosamente para conocer ciertos procesos del pasado si se asumen las características peculiares de estas publicaciones periódicas surgidas como respuesta a circunstancias concretas y sujetas a ciertos mecanismos para su funcionamiento, man- tenimiento y permanencia en el mercado.

Ahora bien, la diversidad temática que ocupa las páginas impresas obedece a una intencionalidad perfectamente explicable si se toman en cuenta dos factores: los generadores y los receptores de los escritos.

Los objetivos que se plantea el editor o responsable, expresados directamente por su pluma o por la de colaboradores permanentes o esporádicos, se van modificando en función de la respuesta del público, de la acogida de los suscriptores, de su alcance dentro y fuera de la localidad donde se 
publica y de la situación política imperante.

Para los lectores de su momento, la prensa era el vehículo a través del cual recibian noticias que les servian de tema de conversación, pretexto de reflexión, norma de conducta, termómetro del sentir y pensar de sus coetáneos, reflejo de problemas económicos, sociales, urbanos, cotidianos, incentivo para ampliar sus horizontes, por ejemplo para abrir mercados, y como ventana al mundo. A todas estas características podemos agregar que, con el paso del tiempo, la prensa adquirió la cualidad de testimonio con un gran valor histórico.

Se ha debatido mucho si la parcialidad de los periódicos no es un impedimento para su aprovechamiento como productores de información pero, como ha dicho Stanley Ross, "el periódico, aunque no sea una fuente irrecusable, sí puede proveernos de un relato continuo de los sucesos contemporáneos de una localidad". 1

Desde 1722 a la fecha, en México se ha publicado un elevado número de periódicos. El objetivo de estas líneas es presentar al lector el Jornal Económico Mercantil de Veracruz, que vio la luz en dicho puerto entre el 1 de marzo y el 31 de julio de 1806 . El periódico, como fuente histórica, ayuda a analizar la situación económica del puerto más importante de entrada y salida del virreinato a fines de la época colonial. También es un simple vehículo para viajar en el tiempo e introducirse en uno de los medios que

${ }^{1}$ Ross, "Historiador", 1965, pp. 347-382. utilizaron los veracruzanos de principios del siglo XIX para estar al día, para formar e informar a la opinión pública.

\section{ANTECEDENTES DEL PERIODISMO}

Desde los inicios de la dominación española, se estableció en México la primera imprenta del nuevo mundo. De sus prensas salieron obras litúrgicas, vocabularios, tratados de ciencias, textos legislativos. Lo que más interesa para nuestros fines es el hecho de que eventualmente, en hojas sueltas o volantes, se daban a conocer "noticias" pormenorizadas de sucesos. El primer ejemplo de estas publicaciones que se conoce es la Relación del espantable terremoto que agora nuevamente ha acontecido en las Indias en una ciudad llamada Guatimala, impresa en 1541 por Juan Pablos.

Dos siglos después, en 1722, el periodismo se formalizó con la Gaceta de México, de Juan Ignacio María de Castorena Ursúa y Goyeneche. Este primer esfuerzo periodístico, aunque breve, se continuó con una segunda Gaceta a cargo de Juan Francisco Sahagún de Arévalo y Ladrón de Guevara, publicada desde 1728 hasta 1742 . Con el mismo nombre de Gaceta volvió a aparecer en 1784, gracias a la iniciativa de Manuel Antonio Valdés, permaneciendo bajo su dirección y la de Juan López Cancelada hasta 1809. Al siguiente año, con el cambio de responsables, se convirtió en órgano oficial del gobierno virreinal.

A estas publicaciones, que contenían noticias cotidianas y describian 
los actos de los gobernantes -aunque todavía sin atreverse a emitir comentarios políticos-, se sumaron otras que han sido englobadas en la categoría de "periódicos científicos", debidos a las iniciativas de José Antonio de Alzate y Ramírez, José Ignacio Bartolache y Diego de Guadalajara Tello. Periódicos como el Diario Literario de México, los Asuntos varios sobre ciencias $y$ artes, las Observaciones sobre la física, historia natural y artes útiles y la Gaceta de Literatura de Alzate; el Mercurio Volante de Bartolache y las Advertencias y reflexiones varias conducentes al buen uso de los relojes grandes y pequeños y regulaciôn, de Guadalajara Tello, sirvieron para instruir a los novohispanos en el marco de la política ilustrada de Carlos III. Al tiempo que fueron una expresión del orgulloso pensamiento criollo que pretendía demostrar los atributos del nuevo mundo, éstos se convirtieron en un medio idóneo de difusión de consejos útiles para el mejor aprovechamiento de los recursos naturales.

En 1805, el Diario de México apareció bajo la dirección de Carlos María de Bustamante y Jacobo de Villaurrutia y provocó el surgimiento de otro tipo de periodismo, el cual se interesó por inspirar una mayor afición a la lectura y proporcionar un medio de comunicación de ideas. La poesía, la crítica social, la descripción de curiosidades, se combinaban con informaciones útiles $\mathrm{e}$ instructivas y con relatos de sucesos políticos. La principal novedad radicó en el hecho de publicarse diariamente; pero además era el órgano de expresión de la "Arcadia
Mexicana", grupo de intelectuales y escritores importantes de la época.

Por otro lado, las publicaciones de contenido económico en Nueva España tienen su antecedente inmediato en la España del siglo XVIII. Ahí se desarrollaron, al calor de la gran inquietud compartida por toda Europa, como un medio para facilitar la tarea de la autoridad monárquica en pro del restablecimiento económico y la educación colectiva. ${ }^{2}$ Eran una respuesta a las necesidades de la surgiente burguesía y, aparte de la información comercial, servían para difundir las nuevas doctrinas de los grandes teóricos. En la segunda mitad del siglo, fueron las sociedades económicas las que promovieron este tipo de periódicos. ${ }^{3}$ En general, dependían para su existencia de publicaciones extranjeras, principalmente inglesas y francesas.

Las publicaciones especializadas en la capital del virreinato de Nueva España comenzaron a ver la luz a principios del siglo pasado. El 1 de diciembre de 1808 salió el primer número del Semanario económico de noticias curiosas y eruditas sobre agricultura y demás artes y oficios, etcétera, fundado por Juan María Wenceslao Sánchez de la Barquera. ${ }^{4}$

2 Enciso, Prensa, 1958, pp. 82-83.

3 Saiz, Jistoria, 1983, p. 111.

"Agücros de la Portilla, "Pcriodismo", 1910, pp. 355-165, 461-462. En cl Diario de Mexico del $15 \mathrm{de}$ marzo de 1808 , se incluía un prospecto para un periódico mexicano semanal que se ascmeja a las características del Semanario. Finalmente, el 27 de noviembre de 1808 , se publicó cl aviso de su próxima aparición. 
Dicho periódico duró con ese nombre hasta el 27 de diciembre de 1810, pues al año siguiente se cambió por el de El Mentor Mexicano. Por otro lado, Juan López Cancelada y José Ruiz Costa publicaron el Correo Semanario Político y Mercantil de México entre el 8 de julio de 1809 y el 30 de octubre de 1811.5

En este contexto surgió un periódico que tiene el enorme mérito de ser el primero publicado fuera de la capital del virreinato. También es el pionero, en Nueva España, dedicado exclusivamente a cuestiones económicas: el Jornal Económico Mercantil de Veracruz, bajo la responsabilidad de Manuel López Bueno.

Hasta donde se sabe, se han conservado dos colecciones completas del periódico, custodiadas en el Fondo Reservado de la Biblioteca Nacional y en la Hemeroteca Nacional, ambas dependencias de la Universidad Nacional Autónoma de México. ${ }^{6}$

5 Zárate, "Juán lópez", 1986, p. 68.

6 En sus acervos se encuentran también algunos ejemplarcs dcl Diario de Veracruz, publicado en la imprenta de Priani y socio en 1822 y 1823 , asi como los números correspondicntes al segundo semestre de 1826 de $\mathrm{El}$ Oriente, diario publicado en Jalapa en la Imprenta del Gobicrno; y finalmente una colección completa de lil Veracruzano, periódico literario saliclo de la imprenta de J. M. Blanco de Veracruz cntre encro y agosto de 1851 . Existc la referencia de otro importante periódico de la región, pero hasta ahora no parece haber side) localizado. Sc trata del Diario Mercantil de Veracruz publicado por José María Almanza entrc el 1 de julio de 1807 y el 8 de julio de 1808 , aparentemente como continuación clel Jomal.
EL. I:IITTOR

Manuel López Bueno y Granda era natural y vecino de Veracruz. ${ }^{7}$ A través de cierta información, inferimos que debió nacer alrededor de 1765. Su padre, Manuel López Bueno y Flores, había pasado de la vieja a la Nueva España en 1732 "a beneficiar diferentes mercaderías de su cuenta y riesgo". Establecido en Veracruz, sirvió por tres décadas en las milicias de este comercio hasta llegar a ser su comandante. Su madre, María Antonia Méndez de la Granda y Herrera, era originaria de Veracruz. Entre la documentación para justificar sus méritos y los de sus mayores, el editor no incluyó datos sobre los abuelos paternos pero sí de los maternos: Ignacio de Herrera Sosa, regidor de la ciudad, descendiente de sus conquistadores y pobladores, Gaspar de Herrera, capitán y alcalde ordinario de primer voto en 1667, y Pedro Munguía Sosa, corregidor y capitán. En esta información es perceptible, una vez más, un patrón común en la formación de la sociedad novohispana: el español comerciante que llega al nuevo mundo y se casa con una criolla de familia establecida.

Manuel López Bueno trabajó durante diez años en los Reales Almacenes de Veracruz, escalando en la jerarquía desde meritorio hasta oficial mayor interventor. Presentó su renuncia an-

7 la información biogräfica ha sido cxt raida, salvo otra inclicación, dcl memorial que Manucl lópc\% Bucno presentó al rey español Carlos IV, lirmado en Veracruz el 30 de novicmbre de 1803. Archivo Gencral de Inclias (en adelante AG1), México, 2511. 


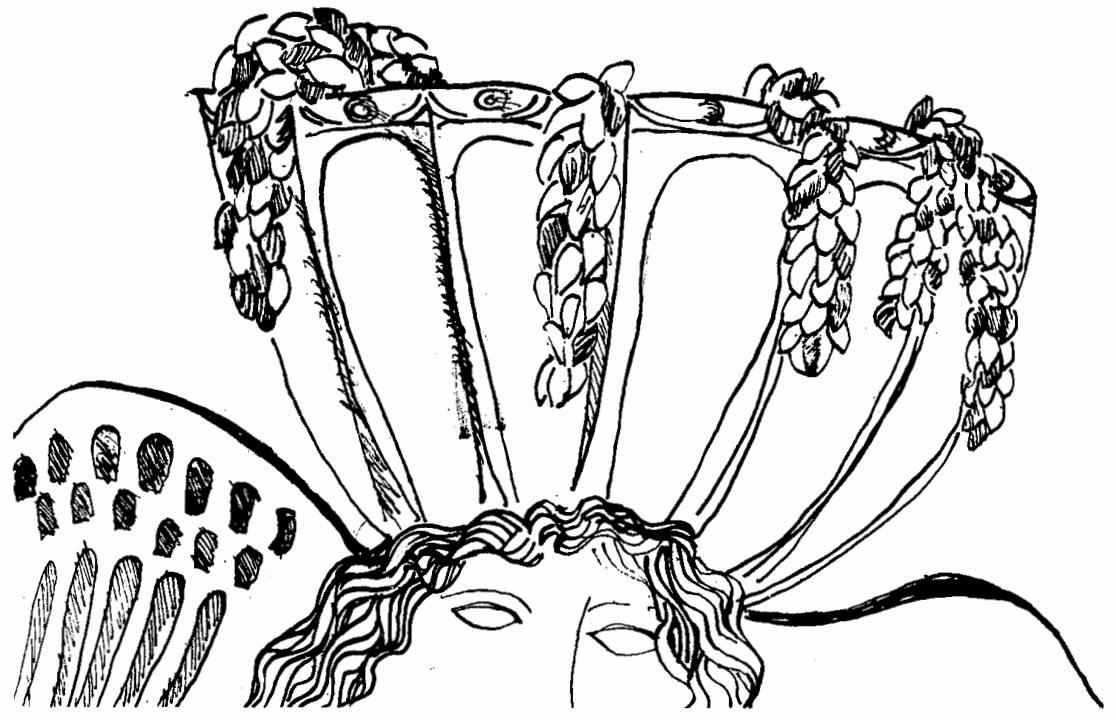

te el virrey Revillagigedo por no ser ascendido a guardalmacén y porque el sueldo le era insuficiente para subsistir "en un país tan caro". Posteriormente, la Justicia y Regimiento de Veracruz lo nombró cabo principal de 117 hombres para el plan de defensa durante la guerra con Inglaterra.

En 1803 explicó que se había propuesto

dar a conocer a mi patria uno de los ramos útiles de que carecia. Establecí en ella, hace 12 años [c. 1791] una imprenta con las correspondientes licencias, sin faltarme el conocimiento de la poca utilidad que me había de proporcionar por ser ésta una plaza puramente mercantil, y carecer de los auxilios de aulas, colcgios, universida- des y otros claustros que producen los sabios escritores y literatos a cuyas continuas tareas deben el sudor de las prensas. $^{8}$

Es interesante el señalamiento de que la empresa no sería productiva por la falta de sabios ávidos de aprovecharla para producir o absorber textos.

Según su propia indicación, introdujo en ese "comercio el uso de varios documentos impresos relativos a su consumo, que hasta aquella época eran desconocidos". Aunque no sabemos a ciencia cierta a cuáles se refiera, suponemos que se trata de "machotes" para las libranzas o de algunas

${ }^{8}$ Ioc. cit. 
balanzas comerciales. De cualquier modo, el primer texto que se conoce de la imprenta ubicada en la sexta calle de Damas en Veracruz, es de 1794 y su contenido fue de carácter religioso.?

Al siguiente año, imprimió la Real Cédula de erección del Consulado de Veracruz por encargo de dicho cuerpo. ${ }^{10}$ Cabe señalar que este hecho motivó el inicio de una prolongada disputa entre el citado tribunal y el virrey Branciforte, ya que se publicó sin su autorización. ${ }^{11}$ Se sabe asimismo que un año después imprimió el Almanak [sic] mercantil o guía de comerciantes para el año de $1796,{ }^{12}$ que es como una especie de "quién es quién". Finalmente se conoce un impreso religioso de 1802 y unas reflexiones sobre el sistema de Broun de $1804 .^{13}$

9 José Toribio Medina lo ha identificado como las Alabanzas al Nombre Santísimo del Gloriosísimo Patriarca Señor Joseph por sus letras iniciales, rcimpreso por Manucl López. Bueno en 1794 y anunciado por la Gazeta de México de ese año. Véasc la Historia, 1958, pp. 453-454.

${ }_{10}$ Real Cedula de Su Majestad para la erección del Consulado de la Muy Noble y Leal Ciudad de Veracruz, Imprenta de Manuel López Bueno, 1795. Reproducida en la obra de Smith, Ramírez Flores y Pasquel, Consulados, 1976, pp. 173-195.

11 Souto, "Consulado", 1989, p. 194.

12 Lama, Imprenta, 1943, p. 7.

13 Novena al antiquísimo contemplativo...San Efrén. Sacala a luz un afecto del santo..., imprenta de D. Manuel López Bueno, Veracruz, 1802 y Reflexiones de Gouiffes sobre el sistema de Broun, traducidas al castellano por D. Florencio Pérez Comoto, López Bueno, Veracruz, 1804. Citadas en Medina, Imprenta, 1904, pp. 13-14.
En los siguientes años, aparte de ocuparse de la publicación del Jornal, y una vez que éste fue suspendido, continuó imprimiendo obras de devoción, convites de entierros y fiestas de Iglesia, y cuantos documentos le proporcionaba el Consulado. El último documento que se conoce de la imprenta corresponde a 1812. José Toribio Medina ha observado que

como esa fecha coincide con su instancia para anular las elecciones capitulares [del ayuntamiento constitucional del puerto], es de sospechar que por causas políticas hubo de salir de Vcracruz o al menos abandonar las tarcas de impresor. ${ }^{14}$

Efectivamente, no se han encontrado referencias suyas posteriores a esa fecha.

Para conocer la impresión, que López Bueno tenía de sí mismo, reproduzcamos parte de uno de sus escritos que se puede considerar como una de esas "relaciones de méritos y servicios" utilizadas para solicitar algún beneficio de las autoridades españolas:

No me corresponde ser panegirista de mis propios hechos, pero permítame

14 Medina, Imprenta, 1904, p. 454. Fl impreso aludido se titula Aviso. Conforme a to consultado por el asesor de este gobierno y por el señor diputado ex presidente de Cortes don José Miguel Guridi y Alcocer se suspende manana dar posesion de los oficios de ayuntamiento a los electos hasta que se decida en justicta el recurso de nulidad inlerpuesto por el ciudadano Manuel Lopez Bueno, Veracruz, 2 de noviembre de 1812, por mandato del señor gobernador, Antonio Figueroa. Citado en Mcdina, Imprenta, op. cit., p. 20. 
v.s. le manifieste con sinceridad que no siendo de aquellos hombres despreciables, polilla de las repúblicas y sí de los que procuran mantener los nobles y honrados sentimientos heredados de sus mayores; que contribuyen al bien del estado y de sus compatriotas, a cuyo éxito he conservado reglada conducta, adquiriendo alguna instrucción en la física, matemáticas, dibujo y otras aplicaciones por las cuales pueda ser útil y adquirir el título de buen ciudadano. ${ }^{15}$

Con toda la obvia carga de subjetividad y el excesivo enaltecimiento de sus virtudes, se refleja en estas letras el carácter emprendedor de su autor.

\section{EL NACIMIENTO DEL JORNAL}

Desde el momento en que Manuel López Bueno decidió dejar de ser un empleado real para acometer una empresa privada, buscó los medios necesarios para combinar la obtención de beneficios particulares y la prestación de servicios a la corona y a los habitantes de su región.

En 1803 se dirigió al Consulado de Veracruz solicitando su apoyo para una serie de propuestas que con anterioridad había presentado y que en ese entonces repetía y enviaba al rey. Él mismo explicó que

con motivo de ser éste el único puerto que franquea el comercio entre España y América, me propuse sería de gran ventaja al mismo comercio el que se

15 AGI, México, 2511, Manuel lópez Bucno a la Junta de Gobicrno del Consulado de Veracru\%, $30 \mathrm{de}$ novicmbre de 1803 . imprimicsen aquí las notas de los cargamentos de buques luego que anclan en el puerto, así porque se propagaría la noticia sin demora en lo interior del reino, como porque se excusarían mu. chos individuos la pensión de repetir las copias manuscritas para remitir a sus corresponsables como lo hacen. 16

Destaca aquí la visión económica de Bueno, consciente de la necesidad de ampliar la información sobre el importante giro del comercio.

Sin embargo, este proyecto fue protestado por Manuel Antonio Valdés, editor de la Gazeta de México, alegando que era una intromisión en el privilegio que tenía como impresor de dicho periódico. López Bueno consideraba que dicha prerrogativa no tenía nada que ver con su petición; en todo caso, Valdés no se hacía acreedor a ella porque al retrasar la publicación de ese tipo de noticias, perjudicaba al comercio y no cumplía con el objeto de servir a la comunidad. Para comprobarlo citaba el cargamento de un barco que había sido publicado en la Gazeta 35 dias después de que había anclado, tiempo en el que la información podía haber corrido ya por todo el reino. Este argumento fue de mucho peso en la concesión de la licencia para publicar el Jornal.

Otra iniciativa suya iba encaminada a la impresión de los bandos publicados en el puerto

proponiendo con esto un auxilio ventajoso de instrucción al que quisicra cstar impuesto de las nuevas órdenes

16 Jbid., Manucl lópcz Bucno al rey, Veracruz, 30 de noviembre de 1803. 
que le deben regir como obligación de todo buen ciudadano, los que encuadernándose por años harían como un código auxiliar y particular del país. ${ }^{17}$

A pesar de contar con el apoyo del intendente, su solicitud se había "traspapelado", por lo que la repitió en 1803 acompañada de otra en donde solicitaba el privilegio de imprimir todo lo relacionado con los ramos de Real Hacienda y Guerra en toda Nueva España, con el título de Impresor de Cámara del Rey.

En la tercera de las solicitudes pidió el monopolio

de lo que corresponda a este real consulado y su comercio en toda su jurisdicción, incluyéndose en este privilegio como relativo a ćl, la impresión de un papel en octavo que abrace las noticias del cargamento de los buques que entran y salen en cste puerto, los precios corrientes de efectos de la plaza, las reales órdenes, premios de seguros, observaciones meteorológicas y otras noticias concernientes y benéficas al comercio y público, saliendo en los dos correos semanarios para todo el interior y exterior del reino. ${ }^{18}$

El hecho de que la iniciativa para la fundación del periódico quedara comprendida en el marco del privilegio de imprimir todo lo relacionado con el Consulado de Veracruz, daba a entender que había una vinculación muy estrecha entre el editor y el tribunal.

Cuando López Bueno se dirigió a la Junta de Gobierno de dicho cuerpo

17 Loc: cit.

18 Loc: cil. pidiéndole apoyo para su representación, le manifestó que lo hacía en consideración al carácter constitutivo del Consulado y con arreglo al artículo 22 de su cédula de erección. Dicho artículo señalaba que la función principal de la Junta sería la protección y fomento del comercio

procurando por todos los medios posibles el adelantamiento de la agricultura, la mejora en el cultivo y beneficio de los frutos, la introducción de las máquinas y herramicntas más ventajosas, la facilidad en la circulación interior, y en suma cuanto parezca conducente al mayor aumento y extensión de todos los ramos de cultivo y trífico. ${ }^{19}$

Hay que hacer notar que estas atribuciones eran muy similares a lo que López Bueno se proponía dar a conocer en su periódico.

El Consulado, una vez estudiada a fondo, no dudó en apoyar su propuesta, y así lo manifestó a Miguel Cayetano Soler, ministro de Hacienda de la corona española en virtud de que

en cllo se intcresa el púlblico comerciante de esta plaza y de todo cl reino, pues no tiene duda que la impresión de los reféridos documentos y especialmente la del periódico mercantil es sumamente útil y curioso por las oportunas noticias que comprenderá. ${ }^{20}$

19 Cédula de creción de 17 de encro de 1795, en Smith, Consulado, 1976, p. 182.

20 AGI, México, 2511, li l Consulado de Veracru\%, represcontado por Juan Felipe de Laurnaga, José ciil de Partcarroyo y José de las Plakas, a Miguel Cayctano Soler, ministro de I Iaciconda, 30 de novicmbre de 1803 . 
Esta mención de informar oportunamente se relaciona con lo apuntado arriba en el sentido de que era vital para el comercio dar a conocer, en el momento preciso y en que fuera de verdadera utilidad, la información de los cargamentos.

El proyecto fue acogido con beneplácito por la corona, aunque le extrañó mucho que la instancia no se le dirigiera por el conducto apropiado, es decir, por medio del virrey. El Consejo manifestó que

el periódico, si se desempeña bien, podrá ser útil y por lo mismo es digno de protección, pero ésta la ha de franquear el virrey sin que el Consulado tenga otra intervención que la de suministrar al autor o autores todas las noticias conducentes para instrucción de los comerciantes. ${ }^{21}$

Por tal afirmación se podría concluir que la corona tal vez no deseaba sancionar la publicación de un periódico que fuera abiertamente el vocero de una corporación tan poderosa, y por ello la sometía a la jurisdicción del virrey. Sin embargo, hay que recordar que las licencias de impresión debían ser sometidas precisamente al máximo gobernante, con la intervención del fiscal de lo Civil de la Real Audiencia. De cualquier manera, la autorización real se dio en marzo de 1804; el Consulado acusó recibo en julio de ese año y fue hasta marzo de 1806 que vio la luz el primer número del periódico. En ese lapso se debieron haber

21 lbid., parcecer del Conscjo sobre periódico de Veracruz, I/4 de marto de 180/. efectuado los trámites ante las autoridades de la capital del virreinato.

Suponemos que el hecho de que la autorización dependiera del virrey debe haber generado algunos conflictos que a la larga podrían llevar a la clausura del Jornal. Sabemos que los periódicos de la capital, la Gazeta y el Diario, tenían continuas dificultades con el máximo gobernante en turno, José de Iturrigaray. Aunque sus conflictos eran más bien de carácter político, ambos quedaron, en un momento dado, sujetos a una estricta vigilancia e incluso a la censura personal del virrey. Ello llevaba implícito un retraso considerable, ya que el gobernante no siempre tenía tiempo de revisar el contenido. Si esto resultaba problemático en la ciudad de México, sería aún peor para un periódico que se encontraba a muchas leguas de distancia. Probablemente estas conjeturas no tengan fundamento, ya que el Jornal respetaba el principio de no involucrarse en el delicado terreno de "la política". Los motivos de su suspensión tal vez estén más relacionados con cuestiones financieras, con el incumplimiento de sus objetivos o con dificultades con las autoridades locales. No hemos encontrado ningún indicio que nos aclare estas dudas ya que, al terminar el primer tomo, simplemente encontramos la palabra "fin".

\section{Características de EI.Jornal.}

Cuando nos referimos a los antecedentes españoles de los periódicos especializados en cuestiones econó- 
micas, mencionamos que muchos de ellos habían nacido al abrigo de las Sociedades Económicas. Ahora bien, hay que apuntar que el Consulado de Veracruz desempeñó un papel importante como junta económica, en cierta forma sustituyendo a las Sociedades de Amigos del País, y en alguna medida estaba propiciando la publicación del Jornal.

Manuel López Bueno, en el "Prospecto" que repartió dando a conocer los objetivos que perseguía con su periódico, señaló que en los países cultos donde existían este tipo de publicaciones, éstas eran muy bien recibidas, y por tanto confiaba en que la suya tuviera una buena acogida si seguía los objetivos de difundir las luces. ${ }^{22}$ Porque, según decía,

la adquisición de las luces y su generalidad, es lenta sin el auxilio de los periódicos, que después de propagarlas y popularizarlas, son unos barómetros fijos que determinan el estado de temperatura culta de una nación.

Ahora bien, ¿quiénes debían ser los receptores de esas luces? A los ojos de López Bueno debía ser "la clase que nos sustenta", el colono, el fabricante, el comerciante, el estadista, y, con mucha pretensión, todo el público de Nueva España. Debemos estar conscientes de que estamos frente a un periódico que emerge en Veracruz,

$22 \mathrm{El}$ "Prospecto de un papel titulado.Jornal Económico Mercantil de Veracruz" está encuadernado al inicio del tomo que contienc los 153 números conocidos del periódico. [il ejemplar que hemos utilizado es el de la Hemeroteca Nacional de la UNAM. una ciudad con características especiales y necesidades particulares pues, como lo ha dicho José Emilio Pacheco, en esa época prácticamente "su muelle de madera es casi el único puente que existe entre Nueva España y Europa. Todo entra y sale por allí. Es la puerta del oro y la plata". ${ }^{23}$ Sin embargo, aunque las inten̉ciones del editor del periódico fueran satisfacer esas necesidades locales, no dejaba de lado la posibilidad de rendir alguna utilidad al lector lejano en el espacio, e incluso en el tiempo. ${ }^{24}$

\section{LECTORES Y AUTORES}

Los periódicos, por lo general, se manejaban con dos tipos de lectores: los fijos, comprometidos permanentemente por medio de una suscripción, y los esporádicos espontáneos, que tenían la libertad de decidir cuándo acercarse a una publicación. Por obvias razones, este grupo es el más dificil de definir, pero de cualquier forma, los lectores reúnen ciertas características: poseen el don de la lectura, tan poco extendido en Nueva España en esos días, el deseo de aumentar su cultura y la posibilidad de aprovechar la información práctica que se les proporciona. Existe, sin embargo, otro grupo de receptores de los conocimientos de los periódicos. Se trata de aquellos analfabetas que se

23 Benítcz y Pacheco, Crónica, 1986, p. 142.

24 Desde las primeras Gacelas, a que nos hemos referido en un apartado anterior, se hace evidente que los editores están conscientes de la utilidad de sus periódicos como fucnte futura para la formación de la historia de su momento. 
reunían en torno a una persona que les leía el contenido de las publicaciones, o de aquellos que escuchaban los comentarios que se hacían en torno a la información.

Para poder dar una idea del tipo de lectores fijos del Jornal, examinamos la lista de suscriptores. En ella encontramos reunidos los nombres de 342 personas e instituciones. Atendiendo a la distribución geográfica de los lectores, encontramos que el $35 \%$ se encontraba en el puerto de Veracruz, el $25 \%$ en la ciudad de México y el resto distribuido de manera desigual en regiones de tráfico mercantil, extracción minera y producción agrícola: las villas y pueblos principales del actual estado de Veracruz, algunos otros puertos del Golfo de México, las haciendas y ciudades del Bajío, la zona Oaxaca-Puebla y los reales mineros del centro-norte. Los lectores más lejanos estaban en Guatemala, Bilbao y Cádiz. Llama la atención no encontrar a lectores radicados en La Habana, a pesar de las ligas comerciales con ese otro puerto. Por otro lado, hay que resaltar que la cifra de suscriptores de Veracruz es considerablemente baja en relación con el resto. Sin embargo, pensamos que los lectores del puerto no tendrían la necesidad de asegurar la recepción del periódico, ya que estaba a su alcance, o incluso iba de mano en mano, lo que no sucedía con los lectores foráneos que debían buscar el medio de obtenerlo con regularidad.

El conjunto de los suscriptores puede ser indicador de las clases sociales a las que pertenecían los interesados en las noticias. Richard Herr ha iden- tificado que los lectores de periódicos españoles a fines del siglo XVIII eran miembros de todos los sectores cultos y acomodados de la sociedad, el clero y la nobleza, aunque no deja de haber una proporción importante de plebeyos. 25

Con algunos de los datos proporcionados por la lista de lectores del Jornal y completando con otras referencias, se descubre un lógico y elevado porcentaje de personas dedicadas a las actividades mercantiles dentro y fuera del puerto, y pertenecientes en su mayoría al Consulado. Destacan los nombres de Pedro Miguel de Echeverría, Gabriel de Iturbe Iraeta, Andrés Gil de la Torre, etcétera.

Llama la atención el hecho de que el siguiente rubro en importancia sea el de los militares. Ello se puede explicar en parte si se recuerda que por esas fechas las fuerzas militares del virreinato se encontraban acantonadas en las inmediaciones de Veracruz. Así, hemos identificado como lectores del periódico al tesorero del cantón de Jalapa, José Alexo de Alegría, el coronel Ignacio Obregón y a Roque de Abarca, brigadier de los reales ejércitos.

También hemos descubierto un número considerable de miembros del alto y del bajo clero (el canónigo José Mariano Beristáin, el cura de Acayucan, Joaquín de Urquiso), algunos letrados (los licenciados Indalesio Bernal y Antonio López de Santa Anna), funcionarios reales (Miguel José Bellido, administrador de la Aduana de Córdoba, Silvestre Díaz de la Vega,

${ }^{25}$ Herr, Espana, 1973, p. 164. 


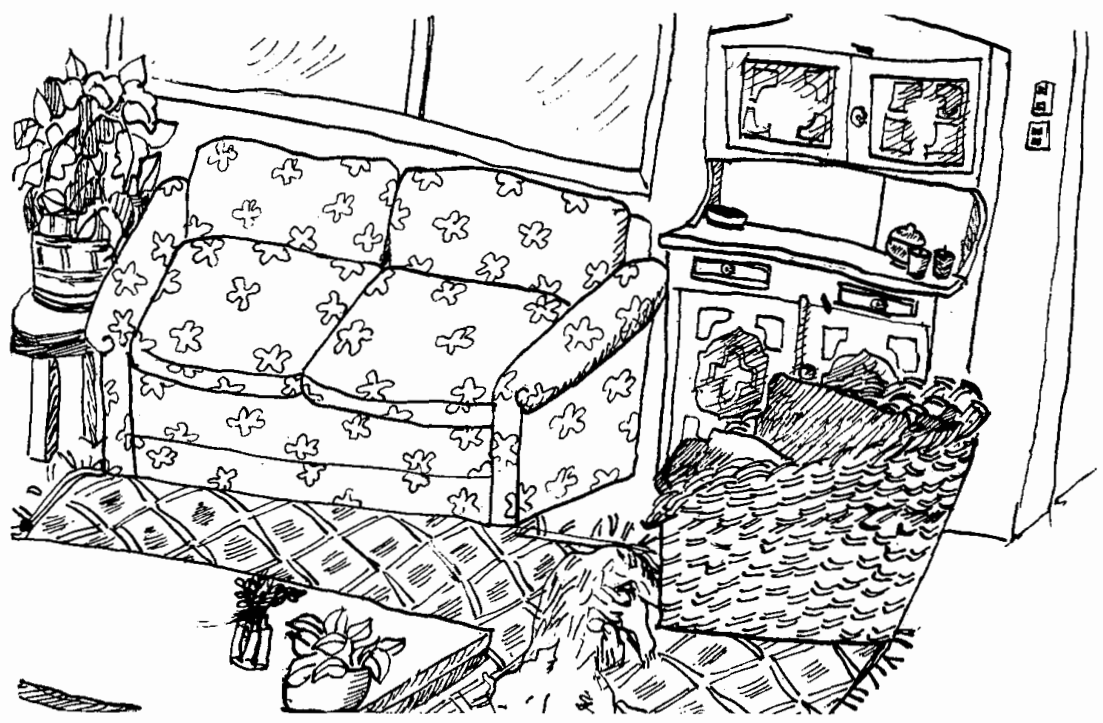

director de la Renta del Tabaco) e instituciones (Consulados de Veracruz, de México y Cádiz, y el Tribunal de Minería).

El porcentaje de lectores con títulos nobiliarios es bastante reducido (el conde de la Valenciana, el mariscal de Castilla y marqués de Ciria y el conde de la Cortina) y se ve superado por los miembros de la Orden de Carlos III. Presentes están también algunos prominentes novohispanos (los que luego serán diputados ante las Cortes de Cádiz, José Miguel Guridi Alcocer, Antonio Joaquín Pérez y Francisco Maniau y Torquemada, el catedrático de botánica, Vicente Cervantes o el escritor Ramón Quintana del Acebo).

Hemos comparado a los suscriptores del Jornal con los del Diario de
México de 1805 y encontramos algunas coincidencias en lectores que seguían ávidamente el desarrollo de los dos periódicos. El Diario, al momento de fundarse, tenía 650 suscriptores, prácticamente el doble de los del Jornal. Si tomamos en cuenta las características del periódico de la ciudad de México, vemos que la proporción de lectores puede ser un indicador positivo de que el periódico veracruzano llegó a tener un amplio alcance. Además, hay que recalcar que existía una cierta vinculación entre las dos publicaciones en el sentido de que se retroalimentaban con información, ${ }^{26} \mathrm{com}$ -

26 Por citar un cjemplo, dircmos que en cl Dicario de México, del 2 de mar»o de $1806, \mathrm{se}$ incluyó el siguicute aviso: " $\Lambda$ yer sc empezaria a 
partían el interés por hacer un tipo de periodismo no exclusivamente dedicado a cuestiones oficiales y gobiernistas; llegaron a demostrar la factibilidad y hasta la necesidad de producir un periódico diario, lo que significó un serio reto para la Gazeta de México.

Pensando en el conjunto de lectores, podríamos descubrir en ellos a los miembros de la sociedad civil y política que aprovechaban el vehículo del periódico para intercambiar sus ideas $y$ posiciones.

La planta de colaboradores del Diario, como ya hemos indicado, incluía a los principales intelectuales novohispanos del momento. No descartamos la posibilidad de que algunos de ellos hayan contribuido con el Jormal cubiertos bajo algún pseudónimo; anagrama o simplemente iniciales. Además de López Bueno, sabemos que escribían para el periódico veracruzano Esteban Berticini, Pedro Vicente Solo o Pedro Ajequiezcane, pero carecemos de mayor información sobre ellos. De los múltiples artículos firmados con iniciales, sólo hemos averiguado que las de P.C.A. corresponden a Pedro Canel Acevedo, abogado y militar asturiano, habitante de la capital del virreinato y suscriptor del Diario de México. ${ }^{27}$ Algunos más están escritos con anagramas y pseudónimos como Prevoat, F.R.B. Rasatlab, Philotecno, Darraonzef, Dr. Camaleón, El Amante de la Verdad, Juan

publicar en Veracruz un nucvo diario intitulado Jornal Económico Mercantil".

27 Justo Sicrra, Antología, momixxxv, pp. 993 y 1075 . Beristáin, dice que estuvo en México hacia 1805 y que escribió sobre política y derecho. Beristáin, Biblioleca, 1947.
Mercader hermano carnal del Minero, etcétera. Finalmente hay artículos que tienen la indicación de ser extractos de obras de algunos extranjeros como Arthur Young, Samuel Marshal, Francisco Craywinchel.

\section{FUIENTES DE: INFORMACIÓN Y FINANCIAMIENTOO}

En el prospecto del periódico, López Bueno mencionó que, para difundir las luces, estaba dispuesto a aprovechar las experiencias de las naciones cultas y adelantadas. No dudaba en extractar o copiar cuantas noticias extranjeras pudiera adquirir. Aparte de los autores extranjeros ya referidos, en algunos de los artículos se menciona la utilización de obras como la $\mathrm{Me}$ dicina doméstica de Buchan, la Geografía moderna de Pinkerton, los Anales políticos del siglo XVIII de Linguet, el Diccionario de Física de Brisson, Dictionnaire des Arts et Métiers y los del padre Terreros y la Real Academia Española.

Es interesante el hecho de que el editor tuviera acceso a obras estadunidenses, inglesas, francesas y españolas. Se sabe que el Consulado tenía proyectada la formación de una biblioteca de obras sobre política económica, e incluso que se elaboró una propuesta de los libros que debían componerla; pero aparentemente no se llegó a fundar. ${ }^{28}$ En caso de que existiera, no sería difícil que López Bueno tuviera la oportunidad de con-

28 Irving y Smith, "Propossed", 1911, pp. 84-102. 
sultarla. De cualquier forma, no hay que olvidar que Veractuz era el puerto de llegada de las mercancías del exterior, y por tanto era el sitio por donde entraban libros, revistas y periódicos. Para el Jornal, se aprovecharon también artículos del Hibernian Magazine, del Journal d'economie rurale, de los periódicos españoles Correo Mercantil de España e Indias, el Semanario de Agricultura y Artes dirigido a los párrocos y el Mercurio de Madrid. Igualmente encontramos citada la Gazeta de Literatura de Alzate y, como ya dijimos, el Diario de México. Aunque aparentemente existía una cierta relación con el periódico La Aurora de la Habana, no hemos encontrado ninguna referencia a noticias extraídas de ahí. ${ }^{29}$

Éstas y otras obras eran las fuentes de las que se extraía la información encaminada a la difusión de conocimientos teóricos y prácticos utilizables por sus lectores. Por distintos conductos, el editor solicitaba la coo. peración de los subdelegados de las intendencias, "consulados, justicias, párrocos y otras personas que quieran contribuir al bien del país". Por ejemplo, la Contaduría de la Real Aduana debía proporcionar listas de precios oficiales, los juzgados le debían notifi-

29 En el Jomal, de 4 de marzo de 1806, se anunció que José Ignacio Bravo recibía suscripciones para La Aurora de la llabana al precio de catorce pesos al año. Dias después, el 22 del mismo mes, se avisó que ya sc había recibido la primera remesa de periódicos y se invitala nuevamente al público a suscribirsc. Sin embargo, en la Gazeta de México del 27 de septiembre de 1806 , se notilicó que los cditores del periódico cubano no reconocían como autorizada dicha suscripción. car sobre los litigios pendientes, etc En el sitio del despacho del Jornal, "bajo de Crisanto González, calle de Juan Muñoz", se instaló un buzón para la recepción de colaboraciones. Las que se enviaran de fuera estarían francas de porte.

La suscripción al periódico era por cuatro, seis o doce meses. Los lectores del puerto lo recibían en su casa. Los demás podían escoger la opción de recibir una remesa cada semana o aprovechando la salida de cualquier correo disponible, lo cual implicaba aumento en el precio. Individualmente cada Jornal costaba medio real, pero si se pagaba una suscripción anual de 21 pesos en el puerto, se tendría un ahorro de un peso y medio. Los precios variaban de una manera muy peculiar, pues costaba lo mismo la suscripción anual para el interior del reino que para España en cada correo disponible, es decir, 29 pesos; las remisiones semanales dentro del virreinato costaban 27 pesos, lo mismo que las mensuales a Campeche, La Habana, islas de Barlovento y España.

Sería interesante conocer si cubiertos los gastos de impresión, pago de operarios y distribución, quedaba alguna ganancia para el editor, pero desgraciadamente, por el momento, no hemos podido encontrar indicios. Lo que sí podemos afirmar es que los suscriptores que pagaban por adelantado, aseguraban de alguna manera el financiamiento del periódico y permitían la impresión de un mayor número de ejemplares que se lanzaban al mercado con la incertidumbre de no venderse. Por otra parte, a mediados de junio de 1806 , se avisó que las suscrip- 
ciones de cuatro meses estaban por concluir y se invitaba a los que quisieran continuar que lo notificaran sin demora. ${ }^{30} \mathrm{El}$ hecho de que a fines del mes siguiente se suspendiera la publicación parece indicar que hubo una deserción de lectores y ello hizo que la empresa expirara. Por la cifra de suscriptores iniciales, inferimos que el tiraje del periódico debió aproximarse a los 500 ejemplares, y tal vez un tiraje menor ya no cubría los gastos básicos. No descartamos, por consiguiente, la idea de que la suspensión del Jornal obedeció a problemas financieros.

En cuanto al diseño y características físicas del periódico, podemos decir que no hay variantes significativas a lo largo de los 153 números. Cada ejemplar tenía cuatro páginas, y su tamaño era del llamado "cuarto de pliego", es decir, 20 centímetros de largo por 13 de ancho. Después del título se ponía la fecha, el santoral, y alguna información religiosa. A continuación se insertaban las noticias relacionadas con el comercio, el listado de cargamentos y precios. En seguida o en sustitución de esta sección, venían los artículos de contenido sobre los diversos temas que apuntaremos líneas más abajo. Cierra el número la sección de avisos, notas y encargos.

TIPO DE NOTICIAS

Las noticias contenidas en el Jornal pueden ser englobadas en tres rubros,

${ }^{30}$ Jornal, 11 de junio de 1806. de acuerdo con lo estipulado en el prospecto: comercio, agricultura y artes. Las presentaremos más adelante atendiendo esta agrupación, pero primero nos ocuparemos de las más generales.

Una de las funciones de la Junta de Gobierno del Consulado de Veracruz era la difusión de información y noticias económicas, bajo la forma de una memoria anual sobre algún tema específico (caminos, algodón, vainilla), o mediante la confección y publicación de las balanzas de comercio maritimo. ${ }^{31}$ Cabe mencionar que estas balanzas fueron recogidas y publicadas por Manuel Lerdo de Tejada. ${ }^{32}$ Inicialmente aparecían cada mes, pero se volvieron anuales. Al final de cada una de ellas se incluian comentarios que eran similares a la información recogida en el Jornal. Cabría preguntarse quién habria copiado a quién.

La Junta tenía igualmente encargada la recopilación de informes estadísticos de las intendencias. Apoyado en una real orden del 21 de junio de 1802 , el virrey ordenó a los intendentes el 28 de enero de 1803 , que remitieran al Consulado de Veracruz un informe elaborado con base en un detallado cuestionario. La idea era conocer la situación económica y social de Nueva España para poder trazar una política comercial adecuada. No se han localizado las respuestas de todas las intendencias, y las que sí se conocen son bastante irregulares. En el Jornal se incluyeron las de Zacatecas, Puebla, Guadalajara, Guanajuato

31 Souto, "Consulado", 1989, p. 88.

32 Icrelo de Tejadla, Aptontes, 1850-58. 
y Nueva Vizcaya. ${ }^{33}$ Tal vez ya no hubo tiempo de publicar las de Sonora y Sinaloa, Veracruz, Coahuila, Durango y San Luis Potosí. Sin embargo, el hecho de hacerlas del conocimiento público mediante el periódico es significativo, porque de este modo los comerciantes en general podían conocer detalladamente otras regiones con las cuales entablar relaciones comerciales.

Por lo que hemos visto, el Jornal podría ser considerado el vocero informal del Consulado de Veracruz. Sin embargo, sentimos que no fue tan aprovechado por ese cuerpo para difundir noticias relacionadas con sus funciones y su jurisdicción como podría esperarse. Son pocos los avisos oficiales que se leen en sus páginas, y casi todos están suscritos por José María Quirós, secretario del Tribunal. Los que se incluyen están relacionados con la recolección del tributo o donativo voluntario para las víctimas de la desastrosa batalla de Trafalgar, ${ }^{3 \cdot 1}$ la reparación del muelle, el auxilio de cables y anclas para los barcos. ${ }^{35}$

En el marco de una preocupación generalizada en el reino por combatir la viruela, en Veracruz se formalizó una campaña de vacunación contra esa enfermedad. En una gran mayoría de los números del Jornal se publica-

33 Las descripciones geográlicas sc localizan en los siguientes números del Jormal: Zacalceas 12 a 14, 18, 20, 21, 24, 26 a 28; Pucbla 33,36 a 40, 43, 45 a 47; Guadahajara 72 a 79; Guanajuato 106 y 143; Nueva Vizeaya 139. Se incluye igualmente una descripción detallada del curato de Cutzamala, 10/-105.

34 Jomal, 4 y 13 de abril de 1806.

35 Ibid., 14 y 25 de mayo de 1806. ba una nota informando el número de vacunados, y notificaba a dónde acudir a inocularse. Esta práctica se había establecido en la ciudad de México desde 1804 gracias a los esfuerzos del virrey Iturrigaray y a la llegada de la expedición médica de Francisco Xavier Balmis. En los dos periódicos de la capital se incluían artículos sobre la enfermedad, métodos curativos, grabados, detalles sobre el número de vacunados en distintas zonas. ${ }^{36}$ Esta preocupación por combatir la viruela no se hacía extensiva, atendiendo a lo publicado en el periódico, al tratamiento de otras enfermedades bastante extendidas en esa zona tan insalubre, como por ejemplo el vómito negro.

En los primeros números del Jornal se incluía una sección encargada de proporcionar el estado de las observaciones meteorológicas. Esto nos pareció lógico y muy útil para prever oportunamente la salida o llegada de los barcos. Sin embargo, números más adelante nos sorprendió que dicha información se reuniera en un estado mensual, dando cuenta de lo sucedido en el pasado. Nuestra lógica nos hace suponer que era más necesario, a los habitantes del puerto, poder estar preparados a futuro que dar a conocer a los lectores externos las indicaciones de termómetro, barómetro y fenómenos pasados. Tal vez tuviera otro significado que no alcanzamos a percibir, relacionado con la previsión a partir de la observación de fenómenos cíclicos.

36 Záratc, "Prensa", 1982, pp. 103-105. 
Lo que sí podemos agregar es que había en esa época un genuino temor por las tormentas eléctricas. En el Diario de México de esos años, se publicaron diversos artículos sobre los efectos de los rayos y la manera de cuidarse de ellos, y el Jornal entró en esa discusión al publicar una noticia sobre los pararrayos. ${ }^{37}$ Las noticias sobre esos incomprensibles fenómenos meteorológicos tendrian tal vez más sentido.

Los historiadores del periodismo, al referirse al Jornal, advierten que tenía un programa limitado a comprender asuntos mercantiles, que nunca se había hecho literatura, aunque sí se encontraban artículos de carácter descriptivo y que, en los primeros números, se había sostenido una disputa en torno a la utilización castellana de la palabra jornal. ${ }^{38}$

Las polémicas entre los periódicos habían comenzado a aparecer desde los tiempos de las publicaciones de Alzate y Bartolache, pero sin ese carácter de contienda política que adquirieron en el siglo XIX. En el Diario de México se utilizaban como una forma de darle movilidad a la infornación y muchas veces el que la iniciaba con un pseudónimo la contestaba con otro, y asi sucesivamente. No descartamos la idea de que lo mismo sucediera en el.Jomal.

La polémica que se ha mencionado sirvió de detonador no sólo para dis-

37 Jornal, 1 de agosto de 1806 . Las noticias dcl Diario son de mayo y junio de 1806 , mayo y scpticmbre de 1807 y junio de 1808.

38 Agücros, "Periodismo", 1916, pp. 155156 y Aintología, t. H, p. 1075. cutir la propiedad de utilizar la palabra "jornal" en lugar de "periódico", sino las funciones y propuestas del mismo. Así pues, el señor P.C.A. criticó que las prensas se ocuparan vanamente de objetos de puro lujo sin que se sacara utilidad alguna. $Y$ agregaba:

Los diarios, si se contienen en su justo deber, son los que ilustran una nación; es decir, mient ras no se rozan con asuntos de gobierno y religión, micntras no se hace un grosero monopolio de sus noticias, o cntrc tanto que no sc forma un cierto número de intrigantes que lo desfigura todo, sobre que hay muchos ejemplares por desgracia nucstra. ${ }^{39}$

Recordemos que Canel Acevedo era un escritor con vivencias españolas y europeas. Tal vez sus observaciones no fueran aplicables para un reino que apenas se iniciaba en la diversificación del periodismo. Sin embargo, sí creía estar en posición de analizar la factibilidad de transmitir conocimientos sobre agricultura y artes en un reino donde, según su opinión, la mayoría de las tierras se desaprovechaban en latifundios yermos y los indios no eran capaces de adelantar.

Las contestaciones a su provocador discurso iban más bien encaminadas a exigirle que fuera más explícito en sus observaciones y que dejara abierta la posibilidad de que otros se ocuparan de los temas que a él parecian no interesarle. (1) Pero no hubo, hasta

39) Jomal, 5 de mar\%o de 1806 .

0 la carta de P.C.A. estí con los núneros 5 y 6 del fomal de 5 y 6 de mar\% de 1806 . Lal primcra réplica es de G.(i.l. y está en el día 8. Dos días después se publicó ot ra carta al respec- 
donde sabemos, ninguna apología del indio, aunque diversos e interesantes temas siguieron debatiéndose en el periódico.

\section{COMERCIO}

Uno de los colaboradores del Jornal observó que "El comercio, esta nueva alma del mundo moral, se ha insinuado en todas partes hasta haberse hecho como esencial a la organización o a la existencia de los cuerpos políticos." 41

Las noticias del ramo de Comercio, según se ofreció en el prospecto, serían sobre sus progresos, los consulados y compañías existentes, los nuevos ramos que se abrieran, el cargamento de las expediciones que salieran y llegaran a Veracruz, el ingreso mensual de esos cargamentos, los fletes de tierra, las mulas cargadas que entraran y salieran, los precios de efectos comerciables y el aviso de la conclusión de algunos negocios.

Haciendo una comparación entre lo que se prometió y lo que se cumplió, se nota que varios de los puntos quedaron sin efecto. Una posible justificación sería la falta de tiempo, ya que en cinco meses no se podria haber dado toda la información deseada. Por ejemplo, no encontramos ningún dato sobre otros consulados existentes en el imperio español. Tampoco

to, firmada por Fstevan Berticini y una de Prevoat. Finalmente el día 16, J.R.13. Rasatlab sugirió terminar la disputa y dedicarsc a copiar escritos doctos sobre los temas en cucstión.

${ }^{4}$ Jornal, 19 de mayo de 1806. hemos visto la relación de las mulas que salieron $y$, en cuanto a las que llegaron, nos llama la atención que sólo se proporcionara el número de animales pero no se dijera la procedencia, el cargamento, su responsable, etc. Tal vez a los veracruzanos les sirviera la información así de escueta pero nosotros, como historiadores, quisiéramos que se ampliara. Lo mismo sucede con lo relacionado con la formación o disolución de compañías de comercio, ya que se reducían a la sección de encargos para que los acreedores y deudores estuvieran enterados, pero no se avisaba de los motivos de su nacimiento o quiebra.

Encontramos, en cambio, varias notas bastante detalladas sobre "Las manufacturas y el comercio de Inglaterra", 12 "El comercio de granos", extractado del informe de Francisco Craywinchel al marqués de Esquilache, 13 y otro "De los progresos del comercio desde su restablecimiento en Europa en el siglo XII hasta su engrandecimiento actual", traducido de la obra de Samuel Marshall. ${ }^{44}$

Canel Acevedo, cumpliendo con el interés manifiesto que tenía por las cuestiones mercantiles, escribió algunos artículos que tituló "Rasgo histórico del comercio". En ellos apuntaba que:

42 Ibid., 18 al 20 de julio de 1806.

43 bid., 9 a 11 de junio de 1806.

4h Ibicl, 25 al $27 \mathrm{de}$ mayo de 1806. la obra dc Marshall is $A$ treaty on the law' of insuran. ce, editada en Beston en 1805. listo nos da una mucstra de que lópco Bueno estaba bastante al día en cuanto a publicaciones extranjeras. 


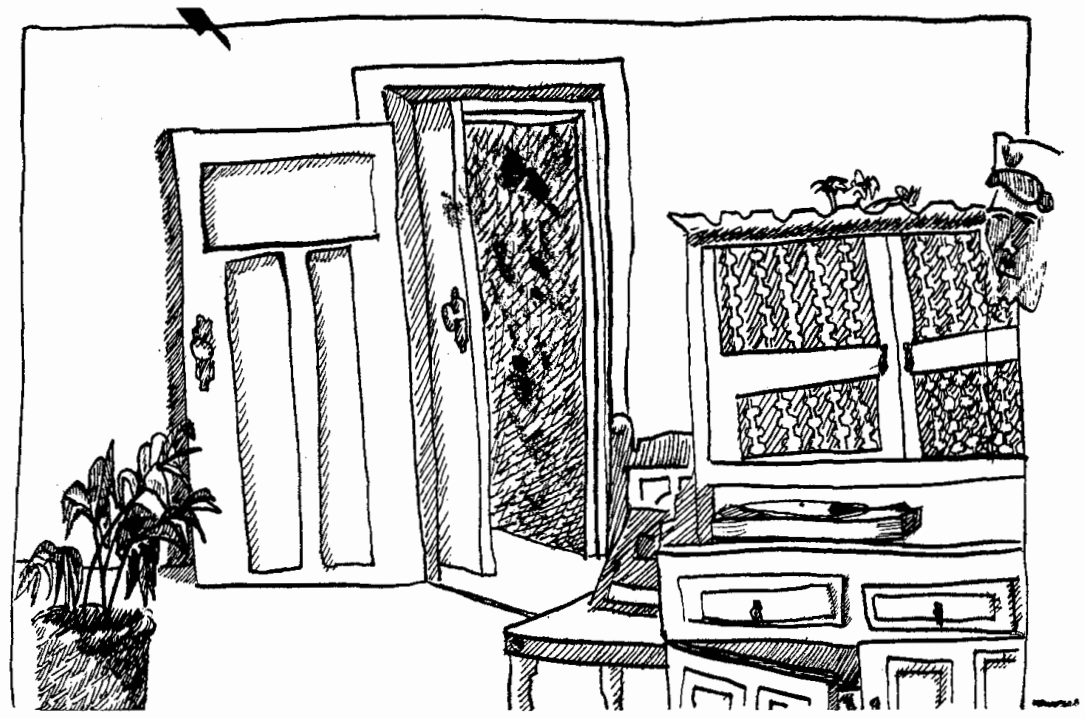

Ia historia del comercio de este reino debe ocupar, sin duda, algunas páginas de su diario. Yo no soy tan vano que me crea poder dar un nuevo tono a este ramo grande; pero ni tampoco tan humilde que me considere absolutamente incapaz de poder recoger alguna cosa de tantas como se han huido a los más despiertos investigadores. ${ }^{45}$

Con una información más basada en la experiencia que en la teoría, proporcionaba puntos de vista muy particulares, dignos de tomarse en consideración por los estudiosos del comercio colonial.

Uno de los tópicos que abarcó mayor espacio en el periódico y que,

${ }^{45}$ Jornal, 29 de mayo al 2 de junio de 1806. como se recordará, fue el origen de su nacimiento, es el relacionado con los informes sobre los cargamentos de los barcos. En uno de los primeros números se solicitó a todos los que despacharan buques, que proporcionaran informes detallados sobre el estado de la embarcación, su tonelaje, "el nombre de sus capitanes y maestres, cuándo deben cerrar sus registros y los precios de sus fletes, según la calidad, cantidad y peso de los distintos efectos que se embarcan". 46

A pesar de esta solicitud, la información no era tan específica y se limitaba en ocasiones a decir el nombre del barco, su destino $u$ origen $y$ a enlistar su cargamento. Aparentemen-

46 Jbikl, 10 de marzo de 1806. 
te hubo repetidos reclamos por no dar cumplimiento cabal al ofrecimiento de proporcionar noticias veraces y oportunas, ya que el editor se vio en la necesidad de aclarar que las notas se retardaban porque no coincidian los registros con los cargamentos. Cuando el apremio fue mayor, decidió publicar la información que tenía, aun con el riesgo de cometer errores. ${ }^{17}$

Tal vez ésta haya sido otra causa de la suspensión del periódico ya que, aparentemente, no cumplía con noticias que eran de sumo interés y en beneficio del buen desempeño del comercio. De cualquier forma, el periódico resulta de enorme utilidad para aquellos que estén interesados en hacer un muestreo de los buques y sus cargamentos en un año en que la guerra con Inglaterra, dueña de los mares, infundía características muy peculiares al tráfico marítimo novohispano.

Se tiene evidencia de que los precios y existencias de los productos "comerciables" en el puerto sufrieron modificaciones precisamente por el estado bélico. El editor advirtió que

mucha parte de los renglones escascan por estar intcrrumpida la navegación con motivo de la presente gucrat. lis cálculo mercantil, que ya giraba sobre la entrada y abundancia de nevit rales, hat variado por lalta de estos registros, causando tal perplejidad y variación en los precios, que de una a otra semana se advicrte notable diferencia. ${ }^{48}$

$17 \mathrm{lbid}, 11 \mathrm{dc}$ abril y 11 de mayo de 1806. $48 \mathrm{Jbid}, 30 \mathrm{dc}$ julis de 1806.
Los índices de inflación pueden ser medidos comparando todas las listas que aparecen en los cinco meses de duración del Jornal.

De acuerdo con lo aparentemente estipulado en la licencia de publicación del periódico, se debía elaborar un estado semanal que manifestara los precios de los abarrotes. Un lector predecía que, si se cumpliera puntualmente con el ofrecimiento, los

resultados fucran felicísimos, pucs como los comerciantes, fabricantes y cosecheros que interesasen en ese comercio suscribirían al Jomal, se lograría en cinco años de paz informar a la nación de los consumos anuales de esta América y de los retornos con las existencias diarias en la plaza. ${ }^{4}$

Ni eran tiempos de paz ni el periódico duró tanto, pero sí es factible conocer a cuánto ascendía el importe de más de 60 productos de importación y exportación. ${ }^{50}$

Para el estudio del comercio resulta igualmente interesante conocer los precios que se pagaban por el transporte terrestre de los efectos. A fines de marzo se publicó el listado del importe de los fletes de tierra para abarrotes y ropas que se transportarin a 22 sitios comprendidos en las cercanías del puerto, la capital del virreinato, la zona Puebla-Oaxaca y el Bajio. ${ }^{51}$ Aparentemente estos precios no sufrieron modificaciones en el lapso que se publicó el periódico, pues no se

4) Ibidl, 18 de abril de 1806 .

50 Véase por cjemplo la lista publicada en el Jormal del 18 de junio de 1806.

51 fomal, 30 de mar\%o de 1806. 
volvieron a repetir. El editor había advertido que no publicaría esa información a menos que se modificara.

Relacionado de alguna manera con el comercio, era el conocimiento de la legislación marítima y la navegación, por lo que el editor incluyó unos artículos encaminados al tratamiento de estos temas. ${ }^{52}$

\section{AgRICULTURA}

En el rubro de la agricultura, lo ofrecido en el prospecto era difundir clescubrimientos y métodos para abono de tierras, plantío de árboles y demás operaciones de la labranza, cria y multiplicación de ganados, escasez o abundancia de frutos, temporales y estado de cosechas, "principalmente de los frutos preciosos como grana, añil, cacao, vainilla, azúcar, algodón, y de las de otras especies subalternas como el maíz", los tiempos, estilos y costumbres de los ajustes o compras, así como los inventos que se adaptasen a los labradores, etcétera.

Como en el rubro anterior, no todos los ofrecimientos se cumplieron. Pero sí se incluyeron diferentes reflexiones y "elogios" en torno a la agricultura, así como observaciones sobre los medios de mejorarla escritas por diversos colaboradores del fornal. 53 Por ejemplo, Canel Acevedo

52 fbicl., 3 y 18 de julio y 28 de abril de 1806.

53 Véanse por cjemplo los siguicntes números dcl/onnal: 11, 12, 17, 18, 20, 21, 22, 24, 25 . 26 , todos del mes de marzo; 60 y 61 de abril 29 y $30 ; 68,71,72,81$ a 85,87 a 91 , todos del mes dc mayo de 1806 . recomendó en uno de sus discursos que se hiciera una mejor distribución de la tierra para que progresara y aumentara la agricultura. Para ello era necesario, igualmente, superar otra traba, la de la falta de comunicaciones porque: "¿Qué hará entonces un hacendado con diez mil fanegas de maíz, por ejemplo, que le sobran y de las que no tiene consumo? Esto debe envilecer por fuerza la agricultura y retrasar sus aumentos." 5 .

El autor estaba consciente de la vinculación entre agricultura y comercio (producción-circulación-consumo) y todas sus propuestas iban encaminadas al fortalecimiento paralelo de las actividades económicas.

Encontramos noticias sobre algunas innovaciones tecnológicas encaminadas a mejorar la agricultura. Una de ellas era un torno para desmontar el algodón inventado por Tomás Quirós, del comercio de Colima. Junto con esta información se incluia una nota del editor del Diario de México en la que afirmaba conocer otras máquinas similares, pero agregaba que la descrita parecía bastante útil. ${ }^{55} \mathrm{En}$ el Jomal se incluyó también la descripción de otra máquina para despepitar, ${ }^{56}$ y una para desgranar maiz. ${ }^{57}$

Igualmente se proporcionaban otro tipo de informes para diversificar la producción agrícola. Se describía, por ejemplo, el método idóneo para la cría de gusanos de seda, ${ }^{58}$ las utili-

\footnotetext{
54 thid., 5 de marzo de 1806 .

$55 \mathrm{Jbial}, 6$ dce abril de 1806.

56 lbiel., 27 dc abril de 1806.

57 biol., 14 de junio de 1806 .

58 Ibial, $23,27,28$ y 29 de junio de 1806.
} 


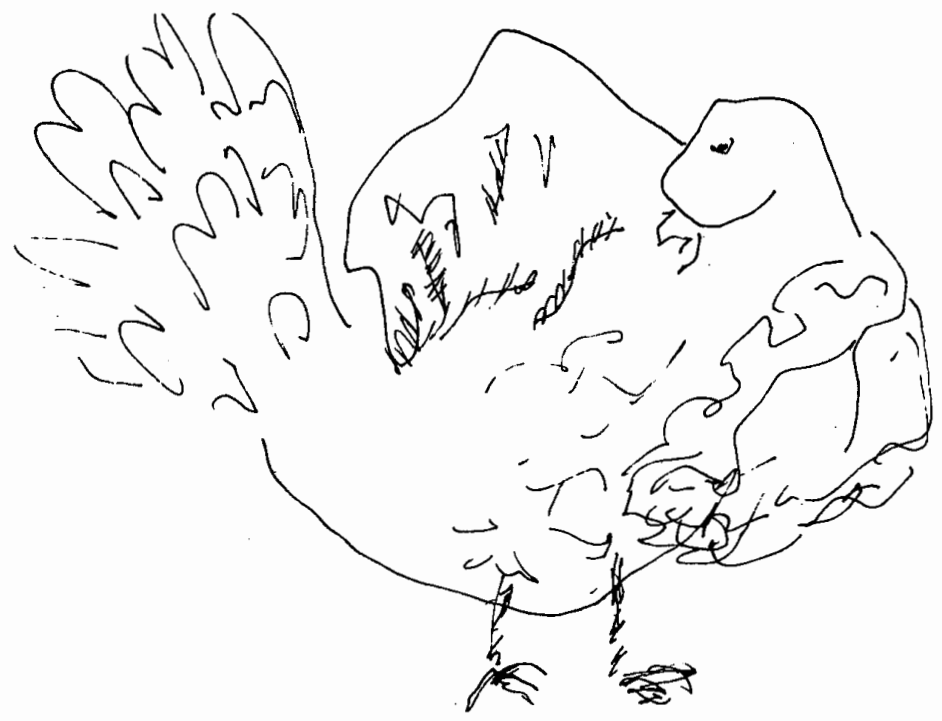

dades del árbol de cera, ${ }^{59}$ el descubrimiento de las plantas llamadas rubia ${ }^{60}$ y yacquina y su aplicación a la medicina, ${ }^{61}$ y la posibilidad de usar el "corazoncillo" como tinte. ${ }^{62}$ Sin embargo, hemos encontrado escasas noticias sobre el tan prometido estado de las cosechas; únicamente se hacen consideraciones en torno a la plaga de la langosta. ${ }^{63}$

Dentro de este ramo de la agricultura, el autor prometió tratar lo relacionado con la "cría y multiplicación

59 lbid., 23 a 25 de marzo; 15 y 16 de abril de 1806.

$60 \mathrm{lbid}, 20$ y 21 de junio de 1806.

61 bict., 29 y 30 de marzo y 30 de junio de 1806.

62 lbid., 8 de mayo de 1806.

$63 \mathrm{lbid}, 14$ a 16 de julio de 1806. de ganados, arreglándonos a nuestra veterinaria". Este ofrecimiento fue cumplido con creces, como lo demuestra la publicación de un elevado número de artículos sobre la conservación y aprovechamiento del ganado vacuno y lanar. ${ }^{6 / 1}$ Por último, se podrían considerar dentro de este grupo, y también del siguiente, los encaminados a explicar el tratamiento y la utilidad de las lanas ${ }^{65}$ y el curtido de cueros. (6) Todo este cúmulo de información puede acercarnos a la agricultura y a la ganadería no sólo de la zona

61 /bid., 13 de mayo; 15 al 20 de junio; 9, 10, 12 y $13 \mathrm{dc}$ julio de 1806 .

65 Ibial, 30 de abril y $1,3,5$ y 6 de mayo de 1806.

66 Ibid, 8 y 9 de mayo de 1806. 
de Veracruz sino, de manera general, del virreinato de Nueva España.

\section{ARTES}

Cabe señalar que el concepto de artes se utiliza aquí de una manera amplia, refiriéndose a la habilidad humana en determinada actividad, principalmente artesanal o manufacturera, y no a las Bellas Artes. En este ramo podrían tener cabida diversos y útiles consejos. Así pues, lo que se proponía López Bueno era hacer ver las mejoras, progresos y adelantamientos hechos en Europa, y particularmente en España, es decir, las nuevas invenciones y modos para simplificar el trabajo y ahorrar costos, la apertura de fábricas, la aparición de nuevas telas, etc. En este rubro tienen cabida temas diversos y aparentemente inconexos, pero todos encaminados a la satisfacción del bien común.

Algunos de los artículos y consejos estaban relacionados con la alimentación. Por ejemplo, se proporcionaba la receta de cómo hacer un escabeche, cómo salar jamones de Navarra y cómo cocer pan. ${ }^{67}$ También se publicó una larga reflexión sobre el "Aguardiente y demás licores espiritosos". 68

Otro grupo interesante de artículos es el que se refiere a las actividades y problemas domésticos. El editor ofrecía remedios para quitar manchas, blanquear ropa y combatir insectos y alimañas como chinches, pulgas, cucarachas, orugas y curar mordidas de

$67 \mathrm{hid}, 18 \mathrm{de}$ mar\%o, $1 \mathrm{dc}$ mayo, 8 dc julio y 20 de abril de 1806 .

$68 \mathrm{hid}, 22$ al 31 de julio de 1806. víbora ${ }^{69}$ Asimismo se proporcionaba información de un jabón para el cutis y algunos afeites más. ${ }^{70}$ Para estar al tanto de los avances en cuanto a nuevas telas y modas y abrir mercados, se escribió sobre el tafetán inglés, vestidos y el arte de la sombrerería. ${ }^{71}$

El análisis detallado de todos los artículos que hemos mencionado podría proporcionar información muy interesante sobre algunos aspectos de la vida cotidiana y doméstica de los habitantes del puerto de Veracruz.

Dentro de lo que podríamos llamar información técnica, el editor se mostró especialmente interesado no sólo en difundir algunos consejos útiles, sino en la enseñanza práctica. Después de describir un método para hacer hules transparentes y opacos manifestó lo siguiente: "El que quiera materialmente aprender todo lo que se va tratando de esta clase en los diarios, siendo para hacerse útil con su ejercicio, ocurra al editor." 72

El mismo ofrecimiento de enseñar se dio para los interesados en el oficio de impresor y grabador. ${ }^{73}$ También se incluían consejos sobre la aplicación del estuco, la utilización y características del carey, la manera de preparar pintura verde, de limpiar libros y estampas y de sacar copias de los escritos. ${ }^{71}$ López Bueno manifestaba lógi-

(9) Ibid, 19, 21 y 23 de mayo, 1 de julio, 9 dc mayo, 21 y 30 de junio y 16 de mayo de 1806.

${ }^{70} \mathrm{lbid}, 9$ de mayo, 21 y 22 de julio de 1806 .

$71 \mathrm{lbid}$, 19 de marzo, 27, 29 y $7 \mathrm{dc}$ abril de 1806.

72 lbid., 29 de marzo de 1806.

73 bid., 17 y 5 dc marzo de 1806.

${ }^{74} \mathrm{lbid}$, 6 de mayo, 26 y 27 de mar\%o, 2 y 7 de abril, 22 de mayo, 30 y 13 de abril de 1806. 
camente un genuino interés por la utilidad de plasmar los conocimientos por escrito, así como por el arte de escribir y el aprovechamiento de las imprentas en la difusión de las luces. En uno de los artículos se hablaba de

este arte ingenioso, que fịja la palabra y el pensamiento, superior al de la escritura, multiplica las copias con tan portentosa rapide $z$ y tan perlecta semejan$\mathrm{za}$, que no conocieron los antiguos a quienes debemos tantos secretos $e$ invenciones útiles. ${ }^{75}$

Quién mejor que un impresor podía suscribir semejante afirmación. Finalmente, mencionaremos que en el periódico se reproducen varios artículos relacionados con la explotación, tratamiento y aprovechamiento de minerales. A pesar de que Veracruz no es una zona que cuente con yacimientos de minerales preciosos, los metales eran una de las principales fuentes de riqueza del virreinato novohispano y sostenían en buena medida al imperio español. En largos textos se hablaba de la plata, del cobre, de cómo platear el cobre, del acero, del carbón mineral y se informaba del establecimiento de una fábrica de hojas de lata en Azcoitia. ${ }^{76}$ Es interesante conocer qué tipo de información se transmitía a los comerciantes que sustentaban

75 Ibid., 1, 2 y 3 de julio de 1806 . Los demás articulos son los siguientes: sobre utilidad de los escritos, 13 de junio, sobre el arte de escribir, 21 dc junio de 1806.

76 Ibicl., 25 de abril, 31 de mayo a 8 dc junio, 29 de julio, $30 \mathrm{de}$ abril, $1,3,18$ a $20 \mathrm{dc}$ mayo, $10 \mathrm{dc}$ junio, 23 y 20 dc julio, 22 y 2.3 de abril y 28 de junio de 1806. parte de su riqueza en la circulación de mercancía y dinero y que buscaban por todos los medios una mejoría de las condiciones del imperio español.

\section{CONSIDERACIONES FINALES}

Ésta ha sido la presentación del Jornal Económico Mercantil de Veracruz, publicado en el puerto en el año de 1806. Su objetivo ha sido destacar el papel de una publicación periódica especializada en asuntos relacionados directamente con el comercio en el puerto de Veracruz, llave de entrada y salida del virreinato novohispano. Consideramos que el muestreo de su contenido resulta lo suficientemente atractivo para que los interesados se acerquen a él y comprendan su utilidad para realizar estudios que traten aspectos económicos y sociales de un virreinato que empieza a vivir el inicio de una inestabilidad que culminará con la separación de España y el nacimiento del México independiente.

Esperamos igualmente que los periódicos novohispanos hayan sido entendidos como el vehículo utilizado por los editores, criollos en su mayoria, para transmitir una cultura dentro del marco.del movimiento generalizado de la Ilustración y para formar la opinión pública.

\section{ARCHIVOS Y BIBLIOGRAFA}

ACI, Archivo General de Indias, Sevilla, México 2511.

-Agüeros de la Portilla, Agustín, "El periodismo en México durante la dominación 
española. Notas históricas, biográlìcas y bibliográficas", Anales del Museo Nacional de Arqueología, Itistoria y Iinología, 3a. época, t. II, 1910, pp. 355-165.

-Benítez, lernando y José Emilio pacheco, Crónica del puerto de Veracruz, Gobicrno del Estado de Veracruz, Veractuz, 1986, 252 pp., ils.

-Beristáin de Souza, José Mariano, Biblioteca IIispanoamericana Septentrional, Ediciones Fuente Cultural, México, 1947, 5 tomos.

- Blázquez Domínguez, Carmen, Una historia compartida. Veracruz, Gobierno del Estado de Veracru\%/Instituto Veracruzano de Cultura/Instituto de Investigaciones Dr. José María Luis Mora, México, $1988,370 \mathrm{pp}$.

-Emery, Edwin, Iil periodismo en los listados Unidos, leditorial l?. 'Trillas, Méxi$\mathrm{co}, 1966,800 \mathrm{pp}$.

- Inciso Recio, luis Miguel, Prensa económica española del siglo Xvill: el Comeo Mercantil de lispaña y sus Indias, Universidad de Valladolid, Valladolid, 1958.

-Herr, Richard, Is/saña y la vevolación del siglo XVIII, Aguilar, Madrid, 1973, 118 pp. (Colccción Cultura c Ilistoria).

-Lama, Josć, La imprenla y el periodismo en el estado de Veracruz, Enríque\% (lalls. grafs. del Gob.), Jalapa, 19/3, 11 pp.

-Lconard, Irving $\Lambda$. y Robert S. Smith, "A proposed library for the merchant guild of Veracruz, 1801", The IIts/sanic American Historical Revien, vol. 24, 1944, pp. 8/1-102.

-L.crdo de 'Jejacla, Manucl, Apuntes históricos de la heroica ciudad de Veracmiz, precedidos de una nolicia de los descubrimienlos hechos en las islas y en el continente americano y de las providencias dicladas por los reyes de lispaña para el gobiemo de sus muevas posesiones, desde el primer viaje con don Crislóbal Colón hasla que se emprendió la conquista de México, Imprenta de Ignacio (implido, México, 1850-58, 3 vols.
-Medina, José Toribio, IIistoria de la imprenta en los antiguos dominios españoles de América y Oceanía, Fondo I listórico y Bibliográfico José Toribio Medina, Santiago de Chile, 1958, 2 tomos.

, La imprenta en Veracruz 1794-1821. Notas bibliográficas, Imprenta Ll\%cviriana, Santiago de Chilc, 1904 (Reimpresión de obras bibliográlicals de José Toribio Medina, t. vi, $\Lambda$ msterdam, N. Isracl, 1961), 34 pp.

-Ross, Stanley Robert, "El historiador y el periodismo mexicano", I/istoria Mexicana, vol. xIv, núm. 3 (55), encro-marıo 1965, pp. 347-382.

-Ruiz Castañeda, María del Carmen, I.uis Reed lorres, Enrique Cordero y Torres, Iil periorlismo en México, 150 años de Hisloria, liditorial Tradición, México, 1971 .

-Saiz, María Dolores, I/islovia del periodismo en lispaña, t. Los origenes. lit siglo $x V I I I$, Alianza Editorial, Madrid, 1983, 292 pp. (Alianza Universidad lextos, 61).

-Sicrra, Justo (comp.), Antología del Cenlenario. Listudio documentado de la lileraiura mexicana durante el primer siglo de independencia. Primera parte 1800-1821, slip, México, MCMi.xxxv, 2 tomos.

-Smith, Robert, José Ramírez lilores y Lconardo Pasqucl, Los Consulados de Comercianles en Nueva lispaña, ıмс., Máxico, 1976 (Scric Ilistoria del Comercio lixtcrior de México).

-Souto Mantecón, Matilde, "lil Consulado de Comerciantes de Veracruz", lesis de macstría en historia, unAM, México, 1989, 257 pp.

-Ircns, Manucl B., IJisloria de Veracruz, linríque\%, Jalapa, 1947-18, tomos II y III.

-Zárate loscano, Vcrónica, "Juan López Cancelada: vida y obra", tesis de macstría en historia, INAM, México, 1986, 21/ pp.

- "Ia prensa mexicana y cl gobicrno del virrey Iturrigaray", tesis de licenciatura en historia, UNAM, México, $1982,162 \mathrm{pp}$. 


\section{SECUENCIA}

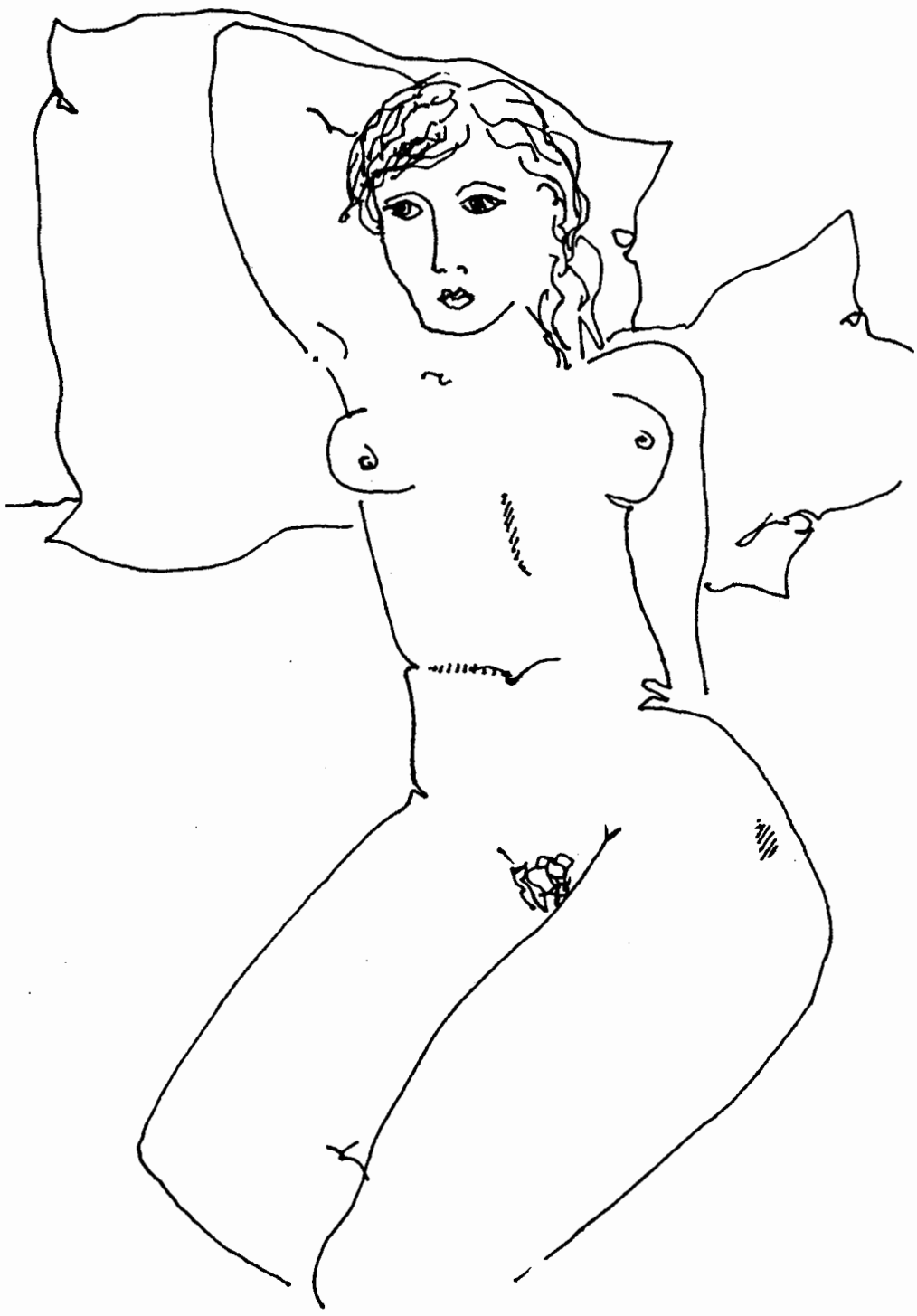

